\title{
FECHAMENTO DAS ESCOLAS RURAIS E TRANSPORTE ESCOLAR NO MUNICÍPIO DE MORRINHOS/GO
}

\author{
CLOSING OF RURAL SCHOOLS AND SCHOOL TRANSPORT IN THE MUNICIPALITY \\ OF MORRINHOS/GO
}

\author{
Flávio Reis Santos ${ }^{1}$ \\ Adriana Maria Silva ${ }^{2}$
}

\begin{abstract}
Resumo
O presente estudo tem por objetivos apontar o fechamento das escolas rurais nas últimas décadas e verificar as condições do transporte escolar fornecido às populações que habitam o meio rural no município de Morrinhos/GO. Optamos por realizar uma pesquisa de campo de cunho exploratório com o emprego de análise quanti-qualitativa dos dados colhidos por meio de informações contidas em documentos oficiais da Secretaria Municipal de Educação, bem como, de informações decorrentes da aplicação de questionários aplicados aos profissionais da educação (secretária de educação, diretores de escola, professores e servidores técnicoadministrativos e técnico-operacionais) sobre o fechamento das escolas rurais, as condições do transporte escolar, os trajetos, as distâncias percorridas diariamente e o tempo gasto nas viagens. Constatamos que o fechamento das escolas no município de Morrinhos retirou de um número substancial de crianças e adolescentes, o direito de acessar e frequentar uma escola próxima à sua moradia. A concentração das escolas no meio urbano prejudica em demasia o processo de formação escolar dos rurícolas. O número de estudantes que completa a educação básica vem diminuindo ano a ano em decorrência das dificuldades por estes enfrentadas, sobretudo, o tempo gasto nas viagens de suas casas para as escolas da cidade.
\end{abstract}

Palavras-Chave: Educação Rural. Educação do Campo. Transporte Escolar.

\begin{abstract}
The present study has for objectives to point the closing of rural schools in recent decades and check the conditions of the school transport provided to the populations that inhabit the rural areas in the municipality of Morrinhos/GO. We chose to conduct a field survey of exploratory nature with the use of quantitative and qualitative analysis of the data collected through information contained in official documents of the City Department of Education, as well as of information arising from the application of questionnaires applied to education professionals (secretary of education, school principals, teachers, technical and administrative servers and operating-technical) about the closure of rural schools the conditions of the school bus, the paths, the distances covered daily and the time spent in travel. We found that the closure of the schools in the municipality of Morrinhos withdrew from a substantial number of children and adolescents, the right of access and attend a school near their home. The

\footnotetext{
${ }^{1} \mathrm{O}$ autor é pós-Doutor e Doutor em Educação pela Universidade Federal de São Carlos UFSCar). Professor do Programa de Pós-Graduação em Ambiente e Sociedade da Universidade Estadual de Goiás (PPGAS/UEG). Pesquisador do Grupo de Estudos e Pesquisas sobre Educação no Campo (GEPEC). Coordenador do Núcleo de Estudos e Pesquisas sobre Educação Rural no Brasil (NEPERBR). E-mail: reisdossantos.flavio@gmail.com ${ }^{2}$ A autora é mestranda do Programa de Pós-Graduação em Ambiente e Sociedade da Universidade Estadual de Goiás (PPGAS/UEG). Especialista em Educação para a Diversidade e Cidadania pela Universidade Federal de Goiás e em Biodiesel pelo Instituto Federal de Educação, Ciência e Tecnologia de Goiás. Graduada em História pela Universidade Estadual de Goiás. Bolsista da Fundação de Amparo à Pesquisa do Estado de Goiás (FAPEG). Email: adrianasilva161@ @otmail.com
} 
concentration of schools in the urban environment harms too much the process of education of the rurícolas. The number of students completing basic education comes decreasing year to year as a result of the difficulties faced by them, above all, the time spent traveling from their homes to the city schools

Keywords: Rural Education. Education Field. School Bus.

\section{INTRODUÇÃO}

Nos últimos anos uma necessidade crescente da criação de políticas destinadas à educação para as populações rurais vem ocupando cada vez mais espaço nas discussões acadêmicas em nosso país, sobretudo, com o propósito de auxiliar e promover a sua inserção no mercado de trabalho do mundo globalizado, sob a concepção de que rural e urbano são partes constituintes da mesma totalidade. Entendemos que na medida em que ocorreu o processo de urbanização e industrialização, bem como, o de mecanização das atividades agropecuárias em todo o território nacional, parte das características essencialmente agrárias tem ficado no passado recente de nossa história,

Embora haja um discurso de que o acesso à educação no Brasil tenha atingido a universalização; são perceptíveis as desigualdades educacionais entre as distintas regiões geográficas brasileiras e, mais especificamente, entre as áreas rurais e urbanas. Após décadas de lutas em prol da elaboração e implantação de políticas públicas que contemplem as necessidades dos sujeitos que residem em áreas rurais, temos assistido nos últimos anos a um sistemático processo de fechamento das escolas do e no meio rural.

Muitas discussões desenvolvidas no meio acadêmico na atualidade tem se ocupado do Programa Nacional de Transporte Escolar (PNATE), que possui por pressuposto assegurar o acesso de estudantes do meio rural à escola (na cidade). A execução do Programa na prática requer mais atenção dos gestores, pois o transporte escolar oferecido aos estudantes do meio rural se contrapõe ao discurso do PNATE, na medida em que os veículos (peruas, vans, ônibus etc.) utilizados para tal finalidade parecem não atender a padrões mínimos de qualidade e segurança para os seus usuários.

Os formuladores e gestores das políticas públicas precisam considerar as realidades e necessidades locais, bem como averiguar e acompanhar de modo efetivo a qualidade e a eficiência dos recursos empregados na e para a escolarização das populações rurais. 
Observamos em nossas análises que o sistemático fechamento das escolas rurais e a utilização do transporte escolar no município de Morrinhos/GO, tem se caracterizado por sua ineficiência, pois boa parte das estradas não é pavimentada (estradas de terra) e aquelas poucas que são não estão bem conservadas. Para complicar ainda mais a situação dos estudantes que utilizam o transporte escolar, os longos percursos (linhas, rotas mal elaboradas/definidas), fazem com que permaneçam fora de suas casas por boa parte do dia e da noite, visto que em muitos casos, tomam o ônibus/van as oito e/ou nove horas da manhã e retornam às suas casas as vinte e/ou vinte e uma horas.

Considerando esse contexto, estabelecemos os seguintes objetivos para empreender esta pesquisa: a) apontar o fechamento das escolas rurais nas últimas décadas no município de Morrinhos/GO; b) investigar as reais condições do transporte escolar fornecido às populações que habitam o meio rural no município de Morrinhos/GO.

Esclarecemos que iniciamos os nossos estudos a partir de rigorosa revisão da literatura, pois entendemos que constitui o ponto de partida de qualquer investigação acadêmico-científica, com vistas a recolher e analisar a maior quantidade possível de informações sobre a temática central do estudo. Concentramos os nossos esforços na escolha de livros, artigos de periódicos científicos, dissertações e teses disponibilizados pelas mais importantes universidades do país (UNICAMP, UFSCar, UNESP, UFU, dentre outras), Periódicos Capes e Google Scholar.

Decidimos empreender uma pesquisa de campo exploratória com o emprego de uma análise quanti-qualitativa dos dados coletados, tanto por meio de informações obtidas em documentos oficiais disponibilizados pela Secretaria Municipal de Educação, quanto por dados decorrentes de questionários semiestruturados, constituídos por dez perguntas fechadas (informações pessoais e profissionais) e cinco perguntas abertas (informações sobre o fechamento das escolas rurais, condições do transporte escolar, trajetos, distâncias percorridas diariamente e tempo gasto nas viagens), aplicados à secretária de educação, diretores de escola, professores e servidores técnico-administrativos e técnico-operacionais.

Optamos pelo emprego de uma análise quanti-qualitativa, pois entendemos que o pesquisador não deve preocupar-se apenas "com a representatividade numérica do grupo pesquisado", mas também com os detalhes fornecidos pelo entrevistado, com as expressões que se encontram nas entrelinhas de suas afirmações, tendo em vista aprofundar a 
compreensão tanto do indivíduo quanto do grupo social pesquisado. (GOLDENBERG, 2007, p. 14).

Além desta introdução este artigo apresenta mais quatro seções, a saber: na seção intitulada "Educação Rural/Educação do Campo", apresentamos as nossas referências teóricas centrais na perspectiva de contextualizar brevemente a temática estudada no decurso histórico de nosso país; na seção "Fechamento das Escolas Rurais" procuramos identificar as escolas rurais que tiveram as suas atividades encerradas no município de Morrinhos/GO a partir da década de 1970; na quarta seção - “Transporte Escolar" - discorremos sobre o Programa Nacional de Apoio ao Transporte Escolar (PNATE) e indicamos os dados sobre as trinta e três linhas do transporte escolar em atividade no município de Morrinhos. Na última seção, procuramos exprimir as nossas considerações acerca da extinção das escolas do campo e sua substituição pelo transporte de crianças e adolescentes para estudarem nas escolas da cidade.

\section{EDUCAÇÃO RURAL/EDUCAÇÃO DO CAMPO}

A histórica ocupação de terras no Brasil nos encaminha à apreensão das desigualdades, uma vez que, não foi proporcionado o acesso a terra para todos que nela trabalham, não lhes foi assegurado o direito à moradia e manutenção digna da existência, da vida. Silva (1998, p. 22) argumenta que o surgimento histórico dos latifúndios é decorrência direta das ações realizadas pela Coroa Portuguesa no "início da colonização do território brasileiro, que ocorreu por meio da doação de grandes extensões de terra a particulares, as denominadas sesmarias". Os contextos que envolveram o Brasil Colonial (1500-1815), o Brasil Imperial (1822-1889) e a primeira fase do Brasil Republicano (1889-1930) mantiveram inalteradas as condições da concentração de terras nas mãos de poucos, enquanto enorme contingente populacional dispunha (dispõe) apenas da venda de sua força de trabalho.

O cenário político-econômico brasileiro sofreu algumas transformações significativas a partir de 1930 em consequência de um golpe de Estado que conduziu Getúlio Vargas à Presidência do Brasil, que por sua vez, colocou em marcha um projeto de industrialização e urbanização do país. A intensificação do discurso de que as indústrias e as cidades representavam o desenvolvimento e o progresso deu início a um segundo processo: o de esvaziamento das áreas rurais. Pela primeira vez em nossa história, a educação para as populações campesinas passava a receber atenção do governo brasileiro, foi neste período que surgiu o movimento denominado ruralismo pedagógico, que possuía por princípios a fixação e manutenção do homem do campo no campo. 
No transcorrer das décadas de 1940, 1950, 1960 e 1970 foram inúmeras as ações por parte do poder público, assim como a emergência de movimentos populares e sociais em defesa de uma educação voltada para populações do meio rural: desde a educação agrícola proposta no Estado Novo (1937-1945) até a pedagogia libertadora de Paulo Freire; e, a Reforma do Ensino de $1^{\circ}$ e $2^{\circ}$ graus instituída pela ditadura civil-militar, que exerceu grande coerção a todos e quaisquer movimentos e manifestações populares nas décadas de 1960 , 1970 e 1980.

$\mathrm{O}$ autoritarismo que caracterizou os governos dos generais presidentes desvanece à medida que a força e atuação dos movimentos sociais, sindicatos, organizações da sociedade civil, instituições de ensino reerguem-se no início dos anos 1980. Destacamos a criação e atuação do Movimento dos Trabalhadores Rurais Sem Terra (MST) que empreendeu luta pela reforma agrária e considerou desde sempre a escolarização de seus partidários fundamental para o trabalho no campo e para a participação na vida política, social e cultural. O processo de defesa e construção da educação do interior do MST percorreu várias etapas e enfrentou inúmeros desafios até a realização do I Encontro Nacional de Educadores na Reforma Agrária (ENERA) em Luziânia/GO no ano de 1997.

Para que possamos entender o surgimento e o desenvolvimento das proposições do MST para a educação do campo, assim como as suas concepções epistemológicas e filosóficas, precisamos considerar “[...] as condições efetivas da realidade, sobretudo quando esse movimento defende uma educação adequada à cultura e à vida dos sujeitos do campo, visando estancar o êxodo rural". (BEZERRA NETO, 2011, p. 112).

Miguel Arroyo (1997) defende que a escola necessária e possível para todos os sujeitos que advém do campo, necessita abandonar a ideia de excluídos e passar a se integrar à sociedade como sujeitos atuantes e participativos do processo ensino-aprendizagem; essa mudança é imprescindível para a sua transformação, na medida em que precisamos:

[...] construir a escola possível para as classes subalternas, temos que a partir da destruição do projeto educativo da burguesia e de seus pedagogos, feito para a constituição de cidadãos-trabalhadores formados à imagem de seus interesses de classe, e para mantê-los nessa condição de classe. (ARROYO, 1997, p. 18).

Segundo Miguel Arroyo, Roseli Caldart e Mônica Molina (2011) “[...] a construção do direito à educação sempre acompanhou a construção da sociedade e dos seus sujeitos que se constroem construindo-a”. De acordo com as Diretrizes Operacionais para a Educação Básica 
nas Escolas do Campo a identidade da escola do campo pode ser estabelecida por sua vinculação às condições materiais, assentada "[...] na temporalidade e saberes, na memória coletiva que sinaliza futuros, na rede de ciência e tecnologia" disponibilizada à sociedade e "nos movimentos sociais em defesa de projetos que associem as soluções exigidas por essas questões à qualidade social da vida coletiva no país". (BRASIL, 2002).

A educação do campo, portanto, vincula-se a um processo de desenvolvimento do sujeito do campo, apesar dos avanços das políticas educacionais, ainda falta muito para uma universalização da educação básica para as populações rurais em direção à superação das desigualdades educacionais, econômicas, sociais. Roseli Caldart (2003) argumenta que a escola na contemporaneidade:

[...] nem sempre se constitui como um lugar de estudo e também não é necessário estar em uma escola para estudar. Mas a escola pode ser um lugar em que se cultive o hábito, a disciplina e o jeito de estudar, especialmente, nas novas gerações. Mas somente fará isto se houver uma intencionalidade dos sujeitos que a ocupam em fazê-la desta forma. (CALDART, 2003, p. 68).

Sérgio Celani Leite (2002, p. 38), por sua vez, infere que "para alguns grupos a escolaridade é meio de manutenção do status quo e para outros significa o processo de independência sociocultural, político e econômico", visto que:

[...] é localmente que se dá a maior participação dos cidadãos e a conjugação de esforços de solidariedade, a fim de enfrentar as desigualdades sociais produzidas no contexto, ainda que esta inserção, por vezes, seja ignorada pelos sistemas de ensino na elaboração dos currículos às escolas rurais. (SOUZA; PINHO; MEIRELES, 2012, p. 356).

Reiteramos que foi a partir da realização do I Encontro Nacional de Educadores na Reforma Agrária, promovido pelo MST com apoio da Universidade Brasília (UnB), Conferência Nacional dos Bispos do Brasil (CNBB), Organização das Nações Unidas para a Educação, Ciência e Cultura (UNESCO), Fundo das Nações Unidas para a Infância (UNICEF) dentre outras instituições da sociedade civil organizada, que o debate sobre a educação do campo ganhou expressão em meio a um contexto caracterizado pela:

[...] negação de direitos, pela intensificação do trabalho e pela precarização das condições existenciais de vida e funcionamento das escolas, os movimentos sociais passaram a denunciar o fechamento das escolas existentes no campo e pautada o Estado e a Sociedade Brasileira quanto a necessidade de ampliação da oferta de escolarização pública e de qualidade social em todos os níveis no campo [...] Em grande medida, as escolas fechadas no campo, são as multisseriadas, envolvidas em 
uma complexidade de aspectos que implicam em sua existência e atuação, enquanto forma predominante de atendimento à escolarização dos sujeitos do campo nos anos iniciais do Ensino Fundamental. (HAGE, 2014, p. 1173).

Salomão Hage (2014, p. 1173) aponta para o fato de que as escolas multisseriadas rurais reúnem alunos de várias idades, séries e níveis numa única classe, “com apenas um professor responsável pela condução do trabalho pedagógico". As escolas rurais multisseriadas e unidocentes se caracterizaram, justamente, pelas diferenças de condições de existência comparadas às escolas urbanas, "onde os estudantes são enturmados por série e cada turma possui o seu próprio professor".

Hage (2014, p. 1173) explica ainda, que essas escolas se constituem na única alternativa de estudo para os sujeitos do campo que se encontram expostos a um conjunto de situações, "que não favorecem o sucesso e a continuidade dos estudos, evidenciando, inclusive, o descumprimento da legislação vigente, que estabelece parâmetros de qualidade a serem alcançados na Educação Básica nas escolas do campo".

\section{FECHAMENTO DAS ESCOLAS RURAIS}

A política de fechamento das escolas rurais no país vem sendo executada de forma sistematizada desde os anos 1980, tendo sido intensificada na década de 1990. O fechamento das escolas rurais e a utilização do transporte escolar para levar os alunos do campo para estudar na da cidade produz uma série de consequências negativas como: o tempo gasto no trajeto de ida e de volta de sua moradia para a escola e vice-versa - na maioria dos casos, o aluno passa o dia fora de casa, o que prejudica a sua concentração e desempenho escolar; aumento no índice de evasão escolar, pois os pais precisam da mão de obra dos filhos para ajudar no trato com a terra e com os animais; contato com uma cultura, que de uma maneira geral, difere da realidade vivenciada pelo rurícola, apesar de sua inserção no mundo tecnologizado; dentre outros fatores que ao invés de promover a formação escolar e a futura participação no mundo do trabalho acaba por excluí-lo.

De acordo com Maria Souza, Maria Fontana e Patrícia Marcoccia (2012) o fechamento das escolas rurais não é mera decorrência de uma fatalidade, exprime em realidade:

[...] a forma como a educação escolar dos sujeitos do campo vem sendo tratada pelos municípios, Estados e União. Apesar de nessa última década haver uma Política Pública Nacional e Estadual da Educação do Campo, formalizada por um aparato jurídico-normativo, a atuação dos governantes revela a fragilidade das medidas, pois 
as legítimas necessidades dos sujeitos do campo não estão sendo supridas. (SOUZA; FONTANA; MARCOCCIA, 2012, p. 103-104).

Para justificar o fechamento das escolas rurais, a Prefeitura de Morrinhos alegou que a maior delas apresentava baixa demanda, ou seja, reduzido número de alunos por unidade de ensino, sendo mais viável para as finanças do município incrementar o transporte escolar, para levar as crianças do meio rural para estudar nas escolas urbanas - Lei Municipal n. 2.282, de 29 de janeiro de 2007. Apesar de a desativação ter sido regulamentada por legislação municipal somente em 2007, o fechamento das escolas rurais em Morrinhos teve início ainda na década de 1970, sendo intensificada nas décadas seguintes, conforme podemos observar nos quadros $1,2,3$ e 4 .

\section{Quadro 1 - Escolas Rurais de Morrinhos Fechadas nas Décadas de 1970 e 1980}

\begin{tabular}{|l|c|c|c|c|}
\hline \multicolumn{1}{|c|}{ Escola } & Região & Funcionamento & Fechamento & Desativação \\
\hline EM Comunidade Santa Rosa & Fazenda Santa Rosa & 1968 & 1975 & Lei $2.282 / 2007$ \\
\hline EM 15 de Novembro & Faz. Mimoso/Várzea & 1970 & 1975 & S/Informações \\
\hline EM João José Barreiro & Fazenda Barreiro & 1973 & 1975 & Lei $2.282 / 2007$ \\
\hline EM Formiga & Fazenda Formiga & 1972 & 1976 & Lei $2.282 / 2007$ \\
\hline EM Patrimônio do Aterro & Fazenda Morro Alto & 1976 & 1977 & Lei $2.282 / 2007$ \\
\hline EM Areias & Fazenda Areia & 1972 & 1979 & Lei $2.282 / 2007$ \\
\hline EM Adriano & Fazenda Piracanjuba & 1973 & 1980 & Lei $2.282 / 2007$ \\
\hline EM São Pedro & Fazenda Mimoso & 1969 & 1982 & S/Informações \\
\hline EM Posto de Monta & Fazenda Santa Rosa & 1967 & 1983 & S/Informações \\
\hline EM Barreiro & Fazenda Barreiro & 1972 & 1983 & Lei $2.282 / 2007$ \\
\hline EM Boa Esperança & Faz. Bom Jd. Barra & 1968 & 1985 & Lei $2.282 / 2007$ \\
\hline EM Bom Jardim da Barra & Faz. Bom Jd. Barra & 1962 & 1985 & Lei $2.282 / 2007$ \\
\hline EM Dona América & Fazenda Piracanjuba & 1980 & 1985 & Lei $2.282 / 2007$ \\
\hline EM Francisco Martins Costa & Fazenda Barreiro & 1989 & 1989 & Lei $2.282 / 2007$ \\
\hline EM Maria Abadia de Jesus & Fazenda Cerradão & 1968 & 1990 & Lei $2.282 / 2007$ \\
\hline EM Vera Cruz & Fazenda Vera cruz & 1988 & 1990 & Lei $2.282 / 2007$ \\
\hline
\end{tabular}

Fonte: Secretaria Municipal de Educação de Morrinhos (SEMED/2016)

Entre as décadas de 1940 a 1980 a Prefeitura de Morrinhos abriu oitenta e três escolas rurais nas mais diversas localidades do município. Para atender as demandas de educação aos sujeitos que viviam no campo foram criadas quarenta e duas escolas no decorrer dos anos de 1961 até 1970. Na década seguinte, mais trinta escolas foram inauguradas em diversas regiões do território morrinhense. No intervalo entre os anos 1981-1990 apenas onze escolas foram abertas, a maior parte das famílias campesinas de Morrinhos tinha próxima e/ou relativamente próxima à sua moradia uma escola rural para atender as suas crianças. 
Quadro 2 - Escolas Rurais de Morrinhos Fechadas de 1990 a 1995

\begin{tabular}{|l|c|c|c|c|}
\hline \multicolumn{1}{|c|}{ Escola } & Região & Funcionamento & Fechamento & Desativação \\
\hline EM Córrego do Retiro & Fazenda Serra & 1958 & 1991 & Lei 2.282/2007 \\
\hline EM Des.Saturnino Azeredo & Fazenda Serra & 1973 & 1991 & Lei 2.282/2007 \\
\hline EM Ponte Grande & Região Ponte Grande & 1966 & 1992 & Lei 2.282/2007 \\
\hline EM Elias Luiz da Silva & Fazenda Serra & 1967 & 1992 & Lei 2.282/2007 \\
\hline EM Alfredo Lopes Morais & BR 153 - Km 130 & 1969 & 1992 & Lei 2.282/2007 \\
\hline EM D. Mariquinha Nunes & Fazenda Santa Rosa & 1970 & 1992 & Lei 2.282/2007 \\
\hline EM Mal. Floriano Peixoto & Fazenda. Baixa Verde & 1972 & 1992 & Lei 2.282/2007 \\
\hline EM Barreiro II & Fazenda Barreiro & 1983 & 1992 & Lei 2.282/2007 \\
\hline EM São Sebast. Vera Cruz & Fazenda Vera Cruz & 1966 & 1993 & Lei 2.282/2007 \\
\hline EM Almas & Fazenda Almas & 1974 & 1993 & Lei 2.282/2007 \\
\hline EM Santa Rosa & Fazenda Santa Rosa & 1980 & 1993 & Lei 2.282/2007 \\
\hline EM Chapadão & Fazenda Chapadão & 1984 & 1993 & Lei 2.282/2007 \\
\hline EM Carlos Melquíades Stos & Fazenda Vera Cruz & 1967 & 1994 & Lei 2.282/2007 \\
\hline EM José Luiz Ferreira & Fazenda Araras & 1969 & 1994 & Lei 2.282/2007 \\
\hline EM Agenor Braga & Fazenda Abreus & 1971 & 1994 & Lei 2.282/2007 \\
\hline EM Serra & Fazenda Serra & 1973 & 1994 & Lei 2.282/2007 \\
\hline EM Santa Cruz & Faz. São Domingos & 1973 & 1995 & Lei 2.282/2007 \\
\hline
\end{tabular}

Fonte: Secretaria Municipal de Educação de Morrinhos (SEMED/2016)

A primeira escola para as populações rurais entrou em funcionamento em 1941 sob a denominação Escola Municipal Sebastião Dionízio de Melo e encerrou suas atividades no ano de 1996. No transcorrer da década de 1940 para a década de 1950 mais duas escolas iniciaram suas atividades: a Escola Municipal Lindolfo Alves Pinto abriu as suas portas em 1950 e é uma das três escolas rurais morrinhenses que ainda se encontra em atividade; e em 1958, a Escola Municipal Córrego do Retiro iniciou o atendimento aos rurícolas da Fazenda Serra e região, suas portas foram cerradas no ano de 1991 (Quadros 2 e 3). Ambas as escolas tiveram sua desativação oficializada em 2007, mediante a publicação da Lei Municipal n. 2.282/2007.

Quadro 3 - Escolas Rurais de Morrinhos Fechadas de 1996 a 2000

\begin{tabular}{|l|c|c|c|c|}
\hline \multicolumn{1}{|c|}{ Escola } & Região & Funcionamento & Fechamento & Desativação \\
\hline EM Sebastião D. de Melo & Faz. Araras & 1941 & 1996 & Lei $2.282 / 2007$ \\
\hline EM Maria José de Jesus & Fazenda Serra & 1970 & 1996 & S/Informações \\
\hline EM Zilda Diniz Fontes & Região Lageado & 1974 & 1996 & Lei $2.282 / 2007$ \\
\hline EM Joaquim B.Souza & Região Araras & 1984 & 1996 & Lei $2.282 / 2007$ \\
\hline EM Joaquim R. de Godoi & Mata dos Godoi & 1989 & 1996 & Lei $2.282 / 2007$ \\
\hline EM Agrícola de Morrinhos & Posto Agropecuário & 1963 & 1997 & Lei $2.282 / 2007$ \\
\hline EM Manoel Isaías & Fazenda Paraíso & 1968 & 1997 & Lei $2.282 / 2007$ \\
\hline EM João Rosa Campos & Fazenda Macacos & 1968 & 1997 & Lei $2.282 / 2007$ \\
\hline EM João Batista de Souza & Fazenda Araras & 1970 & 1997 & Lei $2.282 / 2007$ \\
\hline EM Felício Chaves & Fazenda Tabocas & 1971 & 1997 & Lei $2.282 / 2007$ \\
\hline EM Joana D’Arc & Fazenda Cachoeira & 1973 & 1997 & Lei $2.282 / 2007$ \\
\hline EM Prof. Júlio L. Zedes & Fazenda Serra & 1962 & 1998 & Lei $2.282 / 2007$ \\
\hline EM Piedade & Sombra da Mata & 1967 & 1998 & Lei $2.282 / 2007$ \\
\hline EM Rufino Alves da Silva & Faz. Bom Jd. da Barra & 1969 & 1998 & Lei $2.282 / 2007$ \\
\hline EM Artur da Costa e Silva & BR 153 - Km 123 & 1970 & 1998 & Lei $2.282 / 2007$ \\
\hline EM Manoel L. Mendonça & Fazenda Borá & 1971 & 1998 & Lei $2.282 / 2007$ \\
\hline EM Córrego do Lageado & Fazenda Lageado & 1972 & 1998 & Lei $2.282 / 2007$ \\
\hline
\end{tabular}




\begin{tabular}{|l|c|c|c|c|}
\hline EM Eduardo R. da Silva & Fazenda. Lageado & 1972 & 1998 & Lei 2.282/2007 \\
\hline EM 31 de Março & Fazenda Baixa Verde & 1978 & 1998 & Lei $2.282 / 2007$ \\
\hline EM Divino Pai Eterno & Fazenda Formiga & 1984 & 1998 & Lei $2.282 / 2007$ \\
\hline EM Ma. Amélia M. Almeida & Fazenda Areia & 1966 & 1999 & Lei $2.282 / 2007$ \\
\hline EM Totó Caiado & Fazenda Barreiro & 1969 & 1999 & Lei $2.282 / 2007$ \\
\hline EM Antônio M. Gonçalves & Fazenda Vinagre & 1969 & 1999 & Lei $2.282 / 2007$ \\
\hline EM Joaquim Amaro Silva & Faz. Bom Jd.Flores & 1969 & 1999 & Lei 2.282/2007 \\
\hline EM Juca Rosa & Fazenda Santa Rosa & 1973 & 1999 & Lei 2.282/2007 \\
\hline EM Manoel Agost. Cunha & Fazenda Vinagre & 1973 & 1999 & Lei 2.282/2007 \\
\hline EM Florêncio Cruvinel Lima & Fazenda Piracanjuba & 1985 & 1999 & Lei 2.282/2007 \\
\hline EM Flávio Luiz Saran & Região Três Barras & 1989 & 1999 & Lei $2.282 / 2007$ \\
\hline EM Fco Janúario de Barros & Fazenda Contendas & 1961 & 2000 & Lei $2.282 / 2007$ \\
\hline EM Bertulino Vicente Stos & Fazenda Servânia & 1968 & 2000 & Lei $2.282 / 2007$ \\
\hline EM Samambaia & Fazenda Samambaia & 1970 & 2000 & Lei $2.282 / 2007$ \\
\hline EM Fazenda Mimoso & Fazenda Mimoso & 1972 & 2000 & Lei $2.282 / 2007$ \\
\hline EM Clarindo Jes. Souza & Pov. Jardim da Luz & 1973 & 2000 & Lei $2.282 / 2007$ \\
\hline EM Manoel José do Carmo & Faz. Córrego Fundo & 1974 & 2000 & Lei $2.282 / 2007$ \\
\hline EM 21 de Abril & Fazenda Cerradão & 1976 & 2000 & Lei $2.282 / 2007$ \\
\hline
\end{tabular}

Fonte: Secretaria Municipal de Educação de Morrinhos (SEMED/2016)

No início dos anos 2000, restavam no município de Morrinhos apenas dezenove escolas rurais, mas por pouco tempo, pois em 2001 as Escolas Municipais Rurais Córrego Fundo (Fazenda Córrego Fundo), Padre Primo Scussolino (Fazenda Contendas), São João (Fazenda Buriti do Retiro) e Alamim Vieira de Melo (Povoado Vertente Rica) tinham as suas atividades finalizadas. O processo de fechamento prossegue, em 2002, mais duas unidades escolares têm as suas portas seladas (EM Cândido Matias e EM José Bernardino de Souza) (Quadro 4).

\section{Quadro 4 - Escolas Rurais de Morrinhos Fechadas a partir da Década de 2000}

\begin{tabular}{|c|c|c|c|c|}
\hline Escola & Região & Funcionamento & Fechamento & Desativação \\
\hline EM Córrego Fundo & Faz. Córrego Fundo & 1962 & 2001 & Lei $2.282 / 2007$ \\
\hline EM Pe. Primo Scussolino & Fazenda Contendas & 1965 & 2001 & Paralisada (INEP/2014) \\
\hline EM São João & Faz. Buriti do Retiro & 1969 & 2001 & Lei $2.282 / 2007$ \\
\hline EM Alamim Vieira de Melo & Povoado Vertente Rica & 1972 & 2001 & Paralisada (INEP/2014) \\
\hline EM Cândido Matias & Fazenda Macacos & 1968 & 2002 & Lei $2.282 / 2007$ \\
\hline EM José Bernardino Souza & Fazenda Paraíso & 1973 & 2002 & Paralisada (INEP/2014) \\
\hline EM Uchôa & Fazenda Uchôa & 1961 & 2003 & Lei $2.282 / 2007$ \\
\hline EM Antônio José Lopes & Fazenda Araras & 1967 & 2005 & Lei $2.282 / 2007$ \\
\hline EM Santo Antônio & Faz. Santo Antônio & 1967 & 2005 & Lei $2.282 / 2007$ \\
\hline EM Raimundo M. Pereira & Faz.Bom Jd. Flores & 1968 & 2005 & Lei $2.282 / 2007$ \\
\hline EM Prof. José do Nascto & Fazenda Cerradão & 1969 & 2005 & Lei $2.282 / 2007$ \\
\hline EM Maria Amélia Costa & Fazenda Lageado & 1978 & 2006 & Lei $2.282 / 2007$ \\
\hline EM José Lopes Peres & Fazenda Lageado & 1985 & 2006 & Lei $2.282 / 2007$ \\
\hline EM José Albino Cavalcante & Fazenda Tijuqueiro & 1989 & 2009 & Paralisada (INEP/2014) \\
\hline EM Profa. Ma. L. F. Peixoto & Fazenda Santa Rosa & 1986 & 2010 & Paralisada (INEP/2014) \\
\hline EM S. Dom. Olhos D’Água & São D. Olhos D’ Água & 2007 & 2011 & Paralisada (INEP/2014) \\
\hline EM Lindolfo Alves Pinto & Povoado Marcelânia & 1950 & - & Ativa \\
\hline EM Deusdete Damacena & Pov. Rancho Alegre & 1961 & - & Ativa \\
\hline EM José Cândido da Silva & Trevo de Pontalina & 1968 & - & Ativa \\
\hline
\end{tabular}

Fonte: Secretaria Municipal de Educação de Morrinhos (SEMED/2016) 
Nos anos de 2003, 2009, 2010 e 2011, as Escolas Rurais Uchôa (Fazenda Uchôa), José Albino Cavalcante (Fazenda Tijuqueiro), Professora Maria de Lourdes Ferreira Peixoto (Fazenda Santa Rosa) e São Domingos dos Olhos D’Água (Assentamento São Domingos dos Olhos D’Água), respectivamente, encerraram os seus trabalhos (Quadros 1, 2, 3 e 4).

As Escolas Municipais Padre Primo Scussolino, Alamim Vieira de Melo, José Bernardino de Souza, José Albino Cavalcante, Professora Maria de Lourdes Ferreira Peixoto e São Domingos dos Olhos D’Água não constam na relação de unidades municipais de ensino fundamental situadas na zona rural desativadas pela Lei n. 2.282/2007. O status dessas escolas junto ao Ministério da Educação, de acordo com o Censo Escolar, realizado pelo Instituto Nacional de Estudos e Pesquisas Educacionais Anísio Teixeira em 2014, consta como "paralisadas". (MEC/INEP, 2014).

Das oitenta e quatro escolas que existiram no meio rural no município de Morrinhos desde 1941, apenas três mantêm em funcionamento em nossos dias, conforme podemos observar na Tabela 4: Escola Municipal Lindolfo Alves Pinto, criada em 1950, esta localizada às margens da estrada que liga Morrinhos aos municípios de Rio Quente e de Caldas Novas; Escola Municipal Deusdete Damacena, edificada em 1961, próxima à Rodovia BR 153, que faz a interligação entre os Estados de São Paulo, Minas Gerais e Goiás; e a Escola Municipal José Cândido da Silva, construída em 1968, também nas proximidades da Rodovia BR 153, mais exatamente no Trevo que dá acesso ao município de Pontalina.

\section{TRANSPORTE ESCOLAR}

Nos anos 1980 e 1990, na medida em que houve o fechamento das escolas no meio rural, o transporte dos alunos para as escolas da cidade passou à municipalidade, bem como ao poder público estadual, na conformidade de seus recursos. De acordo com o Inciso VII do Artigo 208 da Constituição de 1988 deve ser assegurado ao educando o atendimento "em todas as etapas da educação básica, por meio de programas suplementares de material didático-escolar, transporte, alimentação e assistência à saúde”.

Em decorrência de algumas inconsistências que geravam interpretação dúbia da legislação, a Lei 10.179, de 31 de julho de 2003 veio modificar o teor da Lei de Diretrizes e Bases da Educação Nacional (LDB 9.394/1996) quanto a responsabilidade e obrigação pelo oferecimento e manutenção do transporte escolar, a saber: “Artigo 10/Inciso VII: Os Estados incumbir-se-ão de assumir o transporte escolar dos alunos da rede estadual” (BRASIL, 2003, Artigo 10, Inciso VII); “Os Municípios incumbir-se-ão de assumir o transporte escolar dos 
alunos da rede municipal” (BRASIL, 2003, Artigo 11, Inciso VI); “Os Municípios poderão optar, ainda, por se integrar ao sistema estadual de ensino ou compor com ele um sistema único de educação básica”. (BRASIL, 2003, Artigo 11, Parágrafo Único).

O Governo Federal instituiu em 2004 o Programa Nacional de Apoio ao Transporte do Escolar (PNATE) por meio da Lei n. 10.880 (09/06/2004), com o objetivo de garantir o acesso e a permanência nos estabelecimentos escolares de ensino fundamental público aos estudantes residentes em área rural mediante a utilização de transporte escolar. Com a publicação da Medida Provisória (MP 455/2009) convertida em Lei de n. 11.947, de 16 de julho de 2009, “o programa foi ampliado para toda a educação básica, beneficiando os estudantes da educação infantil e do ensino médio residentes no meio rural". (BRASIL/FNDE, 2012).

O PNATE garante o repasse de recursos aos Estados e Municípios, realizado em nove parcelas anuais, para custear as despesas do transporte escolar nas redes de ensino público. Esse serviço usualmente é realizado por terceiros, muitas prefeituras por não possuem uma frota suficiente de veículos para assegurar a oferta do serviço e, portanto, promovem processos de licitação para a contratação de empresas privadas para realizar o transporte dos escolares.

O órgão responsável pela normatização e efetividade da aplicação dos recursos do Programa de Transporte Escolar, diretamente ou por delegação, é o Fundo Nacional de Desenvolvimento da Educação (FNDE). Em março de 2007, foi criado pelo Governo Federal um segundo programa, denominado "Caminho da Escola" com o objetivo de conceder aos Estados e Municípios linha de crédito pelo Banco Nacional de Desenvolvimento Econômico e Social (BNDES) para a compra de ônibus, miniônibus, micro-ônibus zero quilômetro e de embarcações novas para o transporte de escolares. (BRASIL/FNDE, 2012).

A implementação de tais programas e/ou políticas públicas têm em contrapartida ao fechamento das escolas rurais, o suposto propósito de combater, ou pelo menos, amenizar as desigualdades regionais e escolares dos sujeitos que vivem em áreas rurais. $\mathrm{O}$ valor per capita/ano do Programa Nacional de Apoio ao Transporte Escolar “[...] varia entre R\$120,73 e R \$ 172,24, de acordo com a área rural do município, a população moradora do campo e a posição do município na linha de pobreza”. (BRASIL/FNDE, 2012).

Alinhado às políticas públicas federais e estaduais, o município de Morrinhos disponibiliza para as populações rurais trinta e três linhas de transporte escolar com rotas que variam de entre 175 e 288 quilômetros, somados trajetos (percursos) de ida e volta. O Quadro 
5 apresenta informações acerca de nove linhas com rotas até $200 \mathrm{~km} /$ dia e com variações de tempo nos trajetos de ida e de volta que variam entre $3 \mathrm{~h} 31 \mathrm{~m}$ e $6 \mathrm{~h} 48 \mathrm{~m}$.

As linhas Barreiro/Marcelânia, Morrinhos/Marcelânia e Trevo Pontalina/José Cândido/Espraiado apresentam a mesma quilometragem somados os trajetos de ida e volta $(190 \mathrm{~km})$, entretanto, devido às condições das estradas, a quantidade de alunos, as condições dos veículos, podemos verificar uma diferença significativa do tempo gasto em cada rota, a primeira em torno de $4 \mathrm{~h} 04 \mathrm{~m}$, a segunda de $3 \mathrm{~h} 31 \mathrm{~m}$ e a terceira de $5 \mathrm{~h} 10 \mathrm{~m}$. Portanto, uma diferença de $26 \mathrm{~m}$ entre a primeira e a segunda linhas/rotas; de $1 \mathrm{~h} 06 \mathrm{~m}$ entre a primeira e a terceira linhas/rotas; e, de $1 \mathrm{~h} 49 \mathrm{~m}$ entre a segunda e a terceira rotas/linhas, apesar da mesma distância percorrida.

As variações também são bastante expressivas quando comparamos as distâncias e os tempos entre as linhas Bom Jardim (118 km em 6h14m), Bom Jardim/Alimentadora (180 km em 6h14m) e Palmito/Vera Cruz (200 km em 5h20m). Podemos constatar que em decorrência da quantidade de estudantes e das dificuldades do trajeto que as duas primeiras linhas/rotas percorrem menores distâncias e consomem proporcionalmente o dobro do tempo se comparadas à terceira linha/rota. Contudo, independente de distância, o fato é que os alunos ficam fora de suas moradias por pelo menos $8 \mathrm{~h} 30 \mathrm{~m}$ se considerarmos, por exemplo, a linha/rota Morrinhos/Marcelânia e chegam a permanecer, $11 \mathrm{~h} 48 \mathrm{~m}$ longe de suas casas se levarmos em conta a linha/rota São Domingos (Quadro 5).

Quadro 5 - Transporte Escolar Município de Morrinhos (até 200 km/dia)

\begin{tabular}{|c|c|c|c|c|c|c|}
\hline Ord. & Empresa & Linha & Proprietário & Km/dia & Alunos & Viagem \\
\hline 1 & $\begin{array}{c}\text { Filho do Rei Trans. } \\
\text { Escolar }\end{array}$ & São Domingos & $\begin{array}{c}\text { Jesus Aparecido } \\
\text { Moreira }\end{array}$ & 175 & 19 & $6 \mathrm{~h} 48 \mathrm{~m}$ \\
\hline 2 & $\begin{array}{l}\text { Gabriel Silva } \\
\text { Arantes }\end{array}$ & IF Goiano & Juscelino Faria Arantes & 178 & 38 & $4 \mathrm{~h} 10 \mathrm{~m}$ \\
\hline 3 & H.B. Transporte & Barreio/Marcelânia & $\begin{array}{c}\text { Benedito Gonçalves de } \\
\text { Souza }\end{array}$ & 190 & 13 & $4 \mathrm{~h} 04 \mathrm{~m}$ \\
\hline 4 & $\begin{array}{l}\text { LI Transporte } \\
\text { Escolar }\end{array}$ & Morrinhos/Marcelânia & $\begin{array}{c}\text { Lindolfo Ferreira da } \\
\text { Costa }\end{array}$ & 190 & 12 & $3 \mathrm{~h} 31 \mathrm{~m}$ \\
\hline 5 & $\begin{array}{l}\text { LM Transporte } \\
\text { Escolar }\end{array}$ & $\begin{array}{l}\text { Trevo Pontalina/José } \\
\text { Cândido/Espraiado }\end{array}$ & $\begin{array}{c}\text { Anderson Fernandes } \\
\text { Ribeiro }\end{array}$ & 190 & 07 & $5 \mathrm{~h} 10 \mathrm{~m}$ \\
\hline 6 & $\begin{array}{l}\text { Melo e Cunha } \\
\text { Trans. Escolar }\end{array}$ & Vinagre/Marcelânia & $\begin{array}{l}\text { Agnaldo Melo da } \\
\text { Cunha }\end{array}$ & 110 & 11 & $4 \mathrm{~h}$ \\
\hline 7 & $\begin{array}{c}\text { Transfelippe Trans. } \\
\text { Escolar }\end{array}$ & Bom Jardim & Sandra Márcia Felippe & 118 & 30 & $6 \mathrm{~h} 14 \mathrm{~m}$ \\
\hline 8 & $\begin{array}{c}\text { Transfelippe Trans. } \\
\text { Escolar }\end{array}$ & $\begin{array}{l}\text { Bom Jardim } \\
\text { (Alimentadora) }\end{array}$ & $\begin{array}{l}\text { Sandra Márcia } \\
\text { Felippe }\end{array}$ & 180 & 30 & $6 \mathrm{~h} 14 \mathrm{~m}$ \\
\hline 9 & $\begin{array}{c}\text { Transporte Pomares } \\
\text { Eireli }\end{array}$ & Palmito/Vera Cruz & $\begin{array}{l}\text { Orlando Matias da } \\
\text { Silva }\end{array}$ & 200 & 19 & $5 \mathrm{~h} 20 \mathrm{~m}$ \\
\hline \multicolumn{5}{|c|}{ Total } & 149 & \\
\hline
\end{tabular}

Fonte: Secretaria Municipal de Educação de Morrinhos (SEMED/2016) 
Aspecto singular que caracteriza a linha Barreiro/Marcelânia (190 km em 4h04m), em que o transporte é realizado totalmente em áreas rurais, tendo como ponto de partida a região do Barreiro e como ponto final o povoado de Marcelânia, local em que está localizada a Escola Municipal Rural Lindolfo Alves Pinto, uma das três unidades escolares rurais, ainda em atividade no município de Morrinhos. A mesma peculiaridade (transito exclusivo nas áreas rurais) é compartilhada pela linha Vinagre/Marcelânia (110 km em 4h00m), porém com algumas distinções, visto que, neste caso, os estudantes no ensino fundamental desembarcam na Marcelânia para frequentar as aulas na Escola Lindolfo, enquanto que os alunos que cursam o ensino médio embarcam em outro ônibus para estudar nas escolas da cidade.

Os dados disponibilizados no Quadro 6 apontam as linhas/rotas que percorrem distâncias entre $201 \mathrm{~km}$ e $250 \mathrm{~km}$, em percursos que chegam a consumir 8h30m na soma dos trajetos de ida e de volta (Serra/Bom Jardim/Vera Cruz - $226 \mathrm{~km}$ - 47 estudantes). Observamos que as linhas Santo Agostinho/Valzinho (202 km - 3h10m - 16 alunos) e Santa Rosa/Cerradão (240 km - 4h20m - 14 alunos) apresentam condições semelhantes quanto às condições das estradas e quantidade de pontos de paradas, na medida em que o número de alunos a ser recolhido pelo transporte escolar é bem próximo.

As condições também são bastante similares ao compararmos as linhas/rotas Barreiro I (202 km - 6h10m - 15 estudantes), Contendas II (206 km - 6h08m - 17 estudantes), Barreiros II (208 km - 6h52m - 14 estudantes) e Cachoeira (210 km - 6h32m - 18 alunos). Entretanto, quando contrapostas as informações sobre a linha Cerradão, que transporta diariamente 33 alunos, percorre uma distância de $246 \mathrm{~km}$ em 6h28m (ida e volta) com as informações da linha Marcelânia/Chapadão, que transporta 23 alunos, percorre uma distância entre os percursos de ida e de volta somados de 236 em 4h20m observamos que as dificuldades são distintas, sobretudo as péssimas condições da estrada da primeira rota.

As divergências podem ser verificadas também, entre as rotas/linhas Arara/Cerradão (238 km - 6h40m - 19 estudantes) e Lageado ( $234 \mathrm{~km}-7 \mathrm{~h} 30 \mathrm{~m}-19$ estudantes), ou entre a linha Contendas ( $242 \mathrm{~km}-7 \mathrm{~h} 20 \mathrm{~m}$ - 25 estudantes) e linha Ponte Nova ( $244 \mathrm{~km}-5 \mathrm{~h} 30 \mathrm{~m}-$ 16 estudantes), apesar da distância entre as duas rotas serem muito próximas, as dificuldades são bem distintas, visto que a diferença do tempo gasto nas viagens das duas rotas é de $2 \mathrm{~h} 10 \mathrm{~m}$.

As convergências nas condições de transporte, das estradas, distância percorrida, tempo de viagem e quantidade de alunos transportados podem ser verificadas ainda, ao 
observamos os dados sobre as linhas Rancho Alegre/Baixa Verde $(250 \mathrm{~km}-7 \mathrm{~h} 00 \mathrm{~m}-22$ estudantes) e Paraíso/Santa Rosa (236 km - 6h40m - 29 estudantes). A nossa maior surpresa decorreu da seguinte das seguintes informações: a linha/rota Capim está a $101 \mathrm{~km}$ da cidade de Morrinhos, portanto, a soma dos trajetos de ida e volta atinge o total de $202 \mathrm{~km}$ (obviamente), 18 estudantes enfrentam diariamente 10 horas de viagem para que possam estudar, o que nos causa demasiado espanto (Quadro 5). Eis a maior e mais inquestionável constatação de que o fechamento das escolas rurais tem prejudicado a formação escolar para a maior parte das populações que vivem no campo.

\section{Quadro 6 - Transporte Escolar Município de Morrinhos (de 201 a 250 km/dia)}

\begin{tabular}{|c|c|c|c|c|c|c|}
\hline Ord. & Empresa & Linha & Proprietário & Km/dia & $\begin{array}{l}\text { Quantidade } \\
\text { de Alunos }\end{array}$ & $\begin{array}{c}\text { Viagem } \\
\text { (Ida/Volta) }\end{array}$ \\
\hline 1 & $\begin{array}{l}\text { APEJN Transp. } \\
\text { Escolar }\end{array}$ & Cerradão & Felippe Antônio Neto & 246 & 33 & $6 \mathrm{~h} 28 \mathrm{~m}$ \\
\hline 2 & Gda Transportes & Santa Rosa/Cerradão & $\begin{array}{l}\text { Geneci B. Dias } \\
\text { Fernandes }\end{array}$ & 240 & 14 & $4 \mathrm{~h} 20 \mathrm{~m}$ \\
\hline 3 & Gda Transportes & Santo Antônio/Valzinho & $\begin{array}{l}\text { Geneci B. Dias } \\
\text { Fernandes }\end{array}$ & 202 & 16 & $3 \mathrm{~h} 10 \mathrm{~m}$ \\
\hline 4 & H.B. Transporte & Barreiro II & $\begin{array}{c}\text { Herculano Vieira } \\
\text { Souza Neto } \\
\end{array}$ & 208 & 14 & $6 \mathrm{~h} 52 \mathrm{~m}$ \\
\hline 5 & $\begin{array}{c}\text { Hamilton Matias } \\
\text { da Silva }\end{array}$ & Barreiro I & $\begin{array}{l}\text { Hamilton Matias da } \\
\text { Silva }\end{array}$ & 202 & 15 & $6 \mathrm{~h} 10 \mathrm{~m}$ \\
\hline 6 & José Aleixo \& Cia & Contendas & José Aleixo da Silva & 242 & 25 & $7 \mathrm{~h} 20 \mathrm{~m}$ \\
\hline 7 & $\begin{array}{l}\text { LF Transporte } \\
\text { Escolar }\end{array}$ & Arara/Cerradão & $\begin{array}{c}\text { Maria Aparecida da } \\
\text { Costa }\end{array}$ & 238 & 19 & $6 \mathrm{~h} 40 \mathrm{~m}$ \\
\hline 8 & $\begin{array}{l}\text { LI Transporte } \\
\text { Escolar }\end{array}$ & $\begin{array}{c}\text { Racho Alegre/Baixa } \\
\text { Verde }\end{array}$ & $\begin{array}{c}\text { Lindolfo Ferreira da } \\
\text { Costa }\end{array}$ & 250 & 22 & $7 \mathrm{~h}$ \\
\hline 9 & $\begin{array}{l}\text { Melo e Cunha } \\
\text { Transp. Escolar }\end{array}$ & Marcelânia/Chapadão & $\begin{array}{c}\text { Agnaldo Melo da } \\
\text { Cunha }\end{array}$ & 236 & 23 & $4 \mathrm{~h} 20 \mathrm{~m}$ \\
\hline 10 & $\begin{array}{l}\text { MMS Transp. } \\
\text { Eireli }\end{array}$ & Ponte Nova & $\begin{array}{c}\text { Márcio Matias da } \\
\text { Silva }\end{array}$ & 244 & 16 & $5 \mathrm{~h} 30 \mathrm{~m}$ \\
\hline 11 & $\begin{array}{l}\text { O. Maciel da } \\
\text { Silva e Cia. }\end{array}$ & Cachoeira & $\begin{array}{l}\text { Otaviano Maciel da } \\
\text { Silva }\end{array}$ & 210 & 18 & $6 \mathrm{~h} 32 \mathrm{~m}$ \\
\hline 12 & $\begin{array}{l}\text { O. Maciel da } \\
\text { Silva e Cia. }\end{array}$ & Capim & $\begin{array}{l}\text { Adenilton Maciel da } \\
\text { Silva }\end{array}$ & 202 & 18 & $10 \mathrm{~h}$ \\
\hline 13 & $\begin{array}{c}\text { Silvério Transp. } \\
\text { Escolar }\end{array}$ & Areia/Santa Rosa & $\begin{array}{l}\text { Divino Eurípedes } \\
\text { Fernandes Leite }\end{array}$ & 225 & 17 & $5 \mathrm{~h}$ \\
\hline 14 & $\begin{array}{l}\text { Silvério Transp. } \\
\text { Escolar }\end{array}$ & Paraíso/Santa Rosa & $\begin{array}{l}\text { Divino Eurípedes } \\
\text { Fernandes Leite }\end{array}$ & 236 & 29 & $6 \mathrm{~h} 40 \mathrm{~m}$ \\
\hline 15 & $\begin{array}{c}\text { Trans Fireball } \\
\text { Transp. Escolar }\end{array}$ & $\begin{array}{c}\text { Serra/Bom Jardim/Vera } \\
\text { Cruz }\end{array}$ & Rildo Faleiro da Silva & 226 & 47 & $8 \mathrm{~h} 30 \mathrm{~m}$ \\
\hline 16 & $\begin{array}{l}\text { Transp. Ferreira } \\
\text { \& Almeida }\end{array}$ & Lageado & $\begin{array}{c}\text { Sinomar Ferreira de } \\
\text { Abreu }\end{array}$ & 234 & 19 & $7 \mathrm{~h} 30 \mathrm{~m}$ \\
\hline 17 & $\begin{array}{c}\text { Transporte Gomes } \\
\text { \& Souza } \\
\end{array}$ & Contendas II & Fábio César Gomes & 206 & 17 & $6 \mathrm{~h} 8 \mathrm{~m}$ \\
\hline \multicolumn{5}{|c|}{ Total } & 362 & \\
\hline
\end{tabular}

Fonte: Secretaria Municipal de Educação de Morrinhos (SEMED/2016) 
O Quadro 7 contém informações sobre sete linhas/rotas que percorrem distâncias acima de $250 \mathrm{~km}$, do mesmo modo que as demais linhas analisadas até aqui, são bastante diferenciadas umas das outras, pois como podemos observar, expressam tempos de viagens que variam entre 6h30m (Mimoso) e 8h52m (Tijuqueiro) com distâncias extremamente próximas: $284 \mathrm{~km}$ e $288 \mathrm{~km}$, respectivamente, apesar de uma diferença significativa entre o número de alunos transportados (10 e 21). Observamos similaridades ao analisarmos os dados da rota/linha Vertente Rica (260 km - 31 estudantes) com viagem em torno de 8h14 (ida/volta) e aqueles da linha Vinagra (284 km - 26 estudantes) e um tempo entre os trajetos de ida e de somados de $8 \mathrm{~h} 20 \mathrm{~m}$. A maior distância percorrida pelos estudantes que residem no meio rural e viajam por nove longas horas para estudar nas escolas da cidade e retornar às suas casas é de $274 \mathrm{~km}$ (Mata dos Godoy).

Quadro 7 - Transporte Escolar Município de Morrinhos (acima de 250 km/dia)

\begin{tabular}{|c|c|c|c|c|c|c|}
\hline Ord. & Empresa & Linha & Proprietário & Km/dia & $\begin{array}{c}\text { Quantidade } \\
\text { de Alunos }\end{array}$ & $\begin{array}{c}\text { Viagem } \\
\text { (Ida/Volta) }\end{array}$ \\
\hline 1 & $\begin{array}{c}\text { H. L. Transporte } \\
\text { Escolar }\end{array}$ & $\begin{array}{c}\text { Rancho Alegre/ } \\
\text { Pontalina }\end{array}$ & $\begin{array}{c}\text { Otaviano Antônio de } \\
\text { Oliveira }\end{array}$ & 269 & 21 & $7 \mathrm{~h} 20 \mathrm{~m}$ \\
\hline 2 & LK Trans. Escolar & Mata dos Godoy & $\begin{array}{c}\text { Leonardo Neves } \\
\text { Romano }\end{array}$ & 274 & 21 & $8 \mathrm{~h} 26 \mathrm{~m}$ \\
\hline 3 & $\begin{array}{c}\text { Márcio Glei } \\
\text { Transporte }\end{array}$ & Tijuqueiro & Márcio Glei de Sousa & 288 & 31 & $8 \mathrm{~h} 14 \mathrm{~m}$ \\
\hline 4 & $\begin{array}{c}\text { Transfelippe } \\
\text { Transp. Escolar }\end{array}$ & Vertente Rica & Sandra Márcia Felippe & 260 & 18 & $6 \mathrm{~h} 40 \mathrm{~m}$ \\
\hline 5 & $\begin{array}{c}\text { Transp. Escolar Boa } \\
\text { Gente }\end{array}$ & Cerradão/Areia & $\begin{array}{c}\text { Delliano da Cruz } \\
\text { Campos }\end{array}$ & 276 & $6 \mathrm{~h} 30 \mathrm{~m}$ \\
\hline 6 & $\begin{array}{c}\text { Transtoquinho } \\
\text { Silveira }\end{array}$ & Mimoso & Paulo Roberto da & 284 & 26 & $8 \mathrm{~h} 20 \mathrm{~m}$ \\
\hline 7 & $\begin{array}{c}\text { Vinagre Transp. } \\
\text { Escolar }\end{array}$ & Vinagre & Silvam Carrijo Freitas & 284 & $\mathbf{1 5 1}$ & 26 \\
\hline
\end{tabular}

Fonte: Secretaria Municipal de Educação de Morrinhos (SEMED/2016)

A quantidade de quilômetros percorridos considerando os dados do Quadro 5 é de 1.531 com 149 estudantes transportados em nove linhas. De acordo com as informações dispostas no Quadro 6 chegamos a 3.847 quilômetros percorridos diariamente com 362 alunos transportados nas dezessete linhas/rotas. O Quadro 7 contém dados que nos permitem chegar ao número de 1.935 quilômetros percorridos por 151 alunos e seus respectivos motoristas de sete linhas. Esses somados atingem as seguintes quantidades/números: 33 linhas que percorrem 7.313 quilômetros e transportam diariamente 662 alunos das mais diversas regiões do município de Morrinhos. Para finalizar a exposição e análise dos dados sobre o transporte 
escolar retornarmos às informações acerca das escolas rurais, que foram sistematicamente fechadas, observamos que as antigas localidades que as abrigavam são exatamente as mesmas que nomeiam as atuais linhas/rotas empregadas no transporte escolar.

\section{CONSIDERAÇÕES FINAIS}

O fechamento das escolas nas mais diversas áreas rurais de Morrinhos retirou de um número substancial de crianças e adolescentes, o direito de acessar e frequentar uma escola próxima à sua moradia. A concentração das escolas no meio urbano prejudica em demasia o processo de formação escolar dos rurícolas. O número de estudantes que completa a educação básica vem diminuindo ano a ano em decorrência das dificuldades por estes enfrentadas, sobretudo, o tempo gasto nas viagens de suas casas para as escolas da cidade.

A extinção das escolas do meio rural não considerou nenhuma voz nas e das comunidades, nenhuma investigação ou estudo científico foi realizado, bem como não foram apontados os critérios utilizados para explicar ou justificar o sistemático fechamento das unidades de ensino, senão aqueles da racionalização de gastos e da inexistência de demanda, apenas para recordar: atualmente são transportados do campo para a cidade mais de 650 alunos no município. Das oitenta e quatro escolas rurais que funcionaram em Morrinhos desde 1941, restaram somente 3,7\%, isto é, três escolas rurais numa área territorial de $2.846 \mathrm{~km}^{2}$, prejuízo irreparável para as populações rurais.

Não podemos deixar de enfatizar que a formação escolar dos sujeitos que vivem no meio rural é fundamental para possibilitar a sua inserção no mercado de trabalho, quer no campo ou na cidade, pois o mundo globalizado e o frenético desenvolvimento técnico e científico tem se tornado cada dia mais exigente. As atividades produtivas no campo acompanham o processo de desenvolvimento tecnologizado da sociedade capitalista contemporânea e requer de forma permanente maior especialização, melhor qualificação da mão de obra, portanto, a educação tem função imprescindível nesse processo.

Assegurar o direito a uma educação de boa qualidade que possibilite ao sujeito a oportunidade de exercer uma atividade produtiva que lhe garanta a existência é dever do Estado, que pode e deve implementar políticas públicas estatais de educação, ou seja, políticas permanentes, políticas que tenham continuidade, que sejam renovadas e melhoradas com a experiência, ou ainda, que sejam substituídas em razão de sua pouca efetividade, eficácia e eficiência - termos amplamente utilizados pelo capitalismo neoliberal, mas pouco considerados quando o assunto é a satisfação das necessidades das populações pobres. 
Concentrar os estudantes nas escolas urbanas, sem considerar o seu cotidiano, as suas necessidades e carências, os hábitos e costumes, a sua materialidade em si, fere os seus direitos básicos e prejudica a sua aprendizagem, sua formação e desenvolvimento cognitivo, pois a exposição às extensas jornadas diárias fora de suas casas, sobretudo, às longas e cansativas viagens em veículos mal conservados que trafegam em estradas em péssimas condições, estradas de terra, trajetos/rotas intermináveis que chegam a manter essas crianças e adolescentes no interior do transporte por até dez horas/dia é, indiscutivelmente, extenuante e consubstancia violação aos seus direitos.

Talvez haja a emergência de restrição à continuidade do fechamento das escolas rurais (do campo), decorrência direta da promulgação da Lei n. 12.960, de 27 de março de 2014, que altera a Lei de Diretrizes e Bases da Educação Nacional (LDB 9.396/1996) e exige do Estado, Município e/ou órgãos competentes, justificativa expressa para o fechamento das escolas do campo, indígenas e quilombolas. Apesar de constituir uma possibilidade de refrear o encerramento da educação para os sujeitos do campo no campo, ainda se faz urgente que a formulação e implementação de políticas públicas estatais considerem a fala das comunidades, que estudos científicos prévios sejam empreendidos para observar e analisar os impactos de tais políticas, dentre outros aspectos relevantes para oferecer e assegurar à população rural brasileira um ensino de boa qualidade. A nossa expectativa com a finalização desta pesquisa é a de que o presente escrito possa contribuir para o debate sobre a educação do e no campo.

\section{REFERÊNCIAS}

ARROYO, Miguel Gonzalez. Escola carente à escola possível. São Paulo, SP: Loyola, 1997. ARROYO, Miguel Gonzalez; CALDART, Roseli Salete; MOLINA, Mônica Castagna (Org.). Por uma Educação do Campo. Petrópolis, RJ: Vozes, 2011.

BEZERRA NETO, Luiz; BEZERRA SANTOS, Maria Cristina dos. (Org.). Educação para o campo em discussão: reflexão sobre a o programa Escola Ativa. São José: Premier, 2001.

BRASIL. Ministério da Educação. Diretrizes operacionais para a educação básica nas escolas do campo. Resolução CNE/CEB n. 1, de 03 de abril de 2002. Disponível em: <http://www.gepec.ufscar.br/textos-1/textos-educacao-do-campo/diretrizes-operacionaispara-a-educacao-basica-nas-escolas-do-campo/view>. Acesso em: 02 abr. 2016.

. Constituição da República Federativa do Brasil. Brasília, DF: Câmara dos

Deputados, Centro de Documentação e Informação, 5 de outubro de 1988. Disponível em: $<$ http://www2.camara.leg.br/atividadelegislativa/legislacao/Constituicoes_Brasileiras/constituicao1988.html/ConstituicaoTextoAtua lizado_EC86.pdf>. Acesso em: 10 nov. 2014. 
BRASIL. Lei de Diretrizes e Bases da Educação Nacional n. 9.394, de 20 de dezembro de 1996. Brasília: Presidência da República/Ministério da Educação, 1996. Disponível em: <http://portal.mec.gov.br/arquivos/pdf/ldb.pdf>. Acesso em: 20 fev. 2015.

Lei n. 10.179, de 31 de julho de 2003. Acrescenta incisos aos artigos 10 e 11 da Lei n. 9.394, de 20 de dezembro de 1996, que estabelece as diretrizes e bases da educação nacional e dá outras providências. Brasília: casa Civil, 2003. Disponível em: <http://www.planalto.gov.br/ccivil_03/leis/2003/L10.709.htm>. Acesso em: 03 mar. 2016.

Lei n. 10.880, de 9 de Junho De 2004. Institui o Programa Nacional de Apoio ao Transporte do Escolar (PNATE) e o Programa de Apoio aos Sistemas de Ensino para Atendimento à Educação de Jovens e Adultos e dá outras providências. Disponível em: <https://www.fnde.gov.br/fndelegis/action/UrlPublicasAction.php?acao=abrirAtoPublico\&sgl _tipo $=$ LEI\&num_ato $=00010880 \&$ seq_ato $=000 \& v 1 r \_a n o=2004 \& s g 1 \_$orgao $=\mathrm{NI}>$ Acesso em: 21 mar. 2016.

Lei $n$. 11.947, de 16 de junho de 2009. Dispõe sobre o atendimento da alimentação escolar e do Programa Dinheiro Direto na Escola aos alunos da educação básica; altera as Leis nos 10.880, de 9 de junho de 2004, 11.273, de 6 de fevereiro de 2006, 11.507, de 20 de julho de 2007; revoga dispositivos da Medida Provisória n ${ }^{\circ}$ 2.178-36, de 24 de agosto de 2001, e a Lei $n^{\circ}$ 8.913, de 12 de julho de 1994; e dá outras providências. Brasília, DF: Casa Civil, 2009. Disponível em:

<https://www.fnde.gov.br/fndelegis/action/UrlPublicasAction.php?acao=abrirAtoPublico\&sgl _tipo=LEI\&num_ato $=00011947 \&$ seq_ato $=000 \& v 1 r \_a n o=2009 \& s g 1 \_o r g a o=N I>$. Acesso em: 06 mar. 2016.

Lei n. 12.960, de 27 de março de 2014. Altera a Lei nº 9.394, de 20 de dezembro de 1996. Faz constar a exigência de manifestação de órgão normativo do sistema de ensino para o fechamento de escolas do campo, indígenas e quilombolas. Brasília, DF: Casa Civil, 2014. Disponível em: <http://www.planalto.gov.br/ccivil_03/_Ato20112014/2014/Lei/L12960.htm>. Acesso em: 02 abr. 2016.

Programa Nacional de Apoio ao Transporte Escolar (PNATE). Brasília: FNDE, 2012. Disponível em: <http://www.fnde.gov.br/programas/transporte-escolar/transporteescolar-apresentacao>. Acesso em: 03 mar. 2016.

CALDART, Roseli Salete. A escola do campo em movimento. Currículo sem Fronteiras, v. 3, n. 1, jan./jun., 2003. Disponível em: <http://www.ia.ufrrj.br/ppgea/conteudo/conteudo-20091/Educacao-MII/3SF/A_ESCOLA_DO_CAMPO_EM_MOVIMENTO.pdf >. Acesso em: 19 mar. 2016.

GOLDENBERG, Míriam. A arte de pesquisar: como fazer pesquisa qualitativa em ciências sociais. 10. ed. Rio de Janeiro, RJ: Record, 2007.

HAGE, Salomão Antônio Mufarrej. Transgressão do paradigma da (Multi)Seriação como referência para a construção da Escola Pública do Campo. Educação e Sociedade, Campinas. V. 35, no 129, p. 1165-1182, out/dez., 2014.

LEITE, Sérgio Celani. Escola rural: urbanização e políticas educacionais. 2. ed. São Paulo, SP: Cortez, 2002.

MORRINHOS (Goiás). Escolas rurais. Morrinhos, GO: SEMED, 2016. 
MORRINHOS (Goiás). Exposição de motivos referentes ao Projeto de Lei n. 2.127, de 5 de janeiro de 2007. Dispõe sobre a desativação de escolas municipais da zona rural e desafeta áreas públicas (Lei n. 2.282/2007). Morrinhos, GO: Câmara Municipal, 2007. Disponível em: <http://www.morrinhos.go.leg.br/novo/wp-content/uploads/2014/01/2.282-Escolas-da-ZonaRural.-Desativao.pdf>. Acesso em: 14 mar.2016.

Transporte escolar. Morrinhos, GO: SEMED, 2016.

PINHO, Sueli Teixeira de; SOUZA, Elizeu Clementino de; MEIRELES, Mariana Martins de. Tensões entre o local e o global: ruralismo contemporâneo e docência em escolas rurais. Revista Educação, Santa Maria, V. 37, nº 2, pp. 351-364, maio/ago. 2012.

SILVA, José Graziano. O que é questão agrária. 3. ed. São Paulo, SP: Brasiliense, 1981. SOUZA, Maria Antônia; FONTANA, Maria Iolanda; MARCOCCIA, Patrícia Correia de Paula. Escolas públicas localizadas no campo no Estado do Paraná: Diretrizes Curriculares e Práticas escolares. Olhar de Professor, Ponta Grossa, v. 15, n. 1, 2012. 